\title{
Une Anglaise défend la Révolution française - Réponse à Edmund Burke
}

\section{Serge Aberdam}

\section{(2) OpenEdition \\ 1 Journals}

Édition électronique

URL : https://journals.openedition.org/ahrf/6623

DOI : $10.4000 /$ ahrf.6623

ISSN : 1952-403X

\section{Éditeur :}

Armand Colin, Société des études robespierristes

\section{Édition imprimée}

Date de publication : 1 juin 2006

Pagination : 250-252

ISSN : 0003-4436

\section{Référence électronique}

Serge Aberdam, « Une Anglaise défend la Révolution française - Réponse à Edmund Burke », Annales historiques de la Révolution française [En ligne], 344 I avril-juin 2006, mis en ligne le 02 juillet 2008, consulté le 23 avril 2022. URL : http://journals.openedition.org/ahrf/6623 ; DOI : https://doi.org/ 10.4000/ahrf.6623

Ce document a été généré automatiquement le 23 avril 2022.

Tous droits réservés 


\title{
Une Anglaise défend la Révolution française - Réponse à Edmund Burke
}

\author{
Serge Aberdam
}

\section{RÉFÉRENCE}

Mary WOLLSTONECRAFT, Une Anglaise défend la Révolution française - Réponse à Edmund Burke, traduction et introduction de Marie-Odile Bernez, notes établies par Marie-Odile Bernez et Marcel Dorigny, Paris, éd. du CTHS, 2003, 482 p., ISBN 2-7355-0532-4, $18 €$.

1 La logique de ce recueil est de regrouper les «principaux écrits sur la Révolution française de Mary Wollstonecraft » soit ici, p. 33-115, sa Défense des droits des hommes, réponse précoce (fin 1790) au célèbre pamphlet de Burke et, p. 119-458, la Vision historique et morale de l'origine et des progrès de la révolution en France et des effets qu'elle a produit en Europe (1794), ainsi que, p. 461-468, deux lettres disjointes (décembre 1792 et février 1793)... L'introduction (p. 9-29) resitue ces documents dans leur contexte et les notes infrapaginales tentent de tirer au clair les allusions de Mary Wollstonecraft et ses sources. Une très courte bibliographie (p. 471-473) ainsi qu'un index (p. 475-480) complètent cette édition commode, qu'orne en couverture un beau portrait détenu par la Tate Gallery. Ce tableau par John Opie, au regard direct, me semble très complémentaire de la lecture des textes.

Par principe, on ne peut qu'applaudir la traduction et publication d'écrits qui n'ont jamais été rendus disponibles en français et qui, présentés au format «de poche", contribuent évidemment à faire mieux comprendre la diversité des réactions anglaises à la Révolution française. On comprend que l'inscription d'œuvres de Mary Wollstonecraft aux programmes des concours de recrutement d'enseignants (agrégation et CAPES d'anglais) a facilité sa redécouverte, et c'est un des aspects positifs de la chose. En anglais, l'ensemble des œuvres de Mary Wollstonecraft, jusqu'à la plus 
mince lettre connue, a été l'objet ces dernières décennies de très belles éditions scientifiques. Le recueil publié par Marie-Odile Bernez n'a aucunement cette prétention. L'introductrice-traductrice s'en explique d'ailleurs p. 17-18: Mary Wollstonecraft est une "autodidacte", une "écorchée vive que l'état du monde fait enrager [...] déchirée entre sa fureur et une volonté de raison. Cela explique sans doute l'inadéquation qui existe parfois entre son style et ses idées [...]. Ce curieux mélange d'une profession de foi rationaliste et d'une fureur irrésistible la rend particulièrement attachante, mais parfois difficile à traduire [...] le texte est émaillé de métaphores outrancières, parfois incohérentes, souvent tirées du domaine animalier, qui sont comme un surgissement de l'inconscient dans un texte qui se veut plus réfléchi [...] ». Tout en tentant de "respecter ces élans ", la traductrice a "aussi pris la liberté de simplifier des formules particulièrement lourdes ou de couper certaines phrases ». Elle a également « évité les archaïsmes délibérés » et «normalisé l'orthographe des noms propres ». Cette gêne devant le style très personnel de Mary Wollstonecraft était déjà apparente dans la seconde traduction française (après celle de 1792) de Défense des droits de la femme, établie par Marie-Françoise Cachin (Payot, 1976, p. 24). Comme souvent, ce genre de travail de simplification sur un texte difficile est effectué au nom du besoin de le rendre « accessible à un public francophone d'aujourd'hui ».

3 Faut-il regretter ce (très relatif!) affadissement de la traduction? Je ne le crois pas. Ceux qui auront besoin d'une lecture érudite ou analytique des textes disposent déjà de l'édition scientifique anglaise de référence, en sept volumes, par Janet Todd et Marylin Butler, que complètent d'autres éditions savantes de fragments dispersés. Les traductions françaises éditées en 1976 et 2003 font ainsi figure de voies d'accès commodes aux textes princeps, plus ardus car plus personnels. Les précautions ainsi prises, en 1976 comme en 2003, afin, dans les deux cas, de se conformer aux attentes de collections « de poche " peu coûteuses, constituent cependant une nouvelle illustration de la dissymétrie des destinées posthumes de l'auteur et de son œuvre dans les deux univers anglophone et francophone.

4 C'est d'ailleurs cette dissymétrie qui représente à mon sens le point aveugle de la présentation par Marie-Odile Bernez : «La rumeur publique fera d'elle une prostituée lubrique et pendant tout le dix-neuvième siècle elle ne sera pratiquement pas republiée [...]» (p. 15). Il me semble qu'il y a là une confusion entre les situations française et anglo-américaine, une sous-estimation de l'écart entre les éditions successives dans les deux univers et l'écho rencontré par l'œuvre de Mary Wollstonecraft. Elle n'a en fait jamais cessé d'être disponible et relue dans ses rééditions anglo-saxonnes, ce qui relativise l'importance de sa "redécouverte " par le mouvement féministe américain des années 1960 (p. 12). En revanche, dans l'univers francophone, la « réhabilitation » de Mary Wollstonecraft par Flora Tristan au milieu du XIX siècle sera l'exception qui confirmera la règle... sans pour autant mener à une quelconque réédition en français jusqu'à notre époque.

5 Sur les textes eux-mêmes, dont l'appareil de notes facilite l'accès, il est clair qu'une traduction de la Vindication of the Rights of Men manquait, depuis l'origine, parmi les écrits de ceux qui, en Angleterre, ont rompu des lances en faveur de la Révolution. On remarque globalement le cran avec lequel Wollstonecraft relève le défi lancé par Burke, son assurance et sa volonté de convaincre, mais aussi les quelques pages (p. 91-94) qui annoncent dès 1790 les thèmes de la bien plus ambitieuse Vindication of the Rights of Woman de 1792. 
6 À côté de cet important pamphlet, le texte qui sans pour autant être signalé dans le titre occupe $70 \%$ de la pagination du recueil, la Vision historique et morale... présente un autre type d'intérêt. C'est un exemple d'écriture d'une histoire presque immédiate des débuts de la Révolution par une personne qui ne l'avait suivie que de Londres. Les récentes journées d'étude tenues en septembre 2005 à Vizille ont judicieusement porté l'attention sur ces productions historiographiques initiales. L'accueil assez mitigé que devait recevoir cette œuvre, jugée dès l'époque trop proche d'une compilation de la presse anglaise, fait qu'elle a été assez unanimement comptée pour mineure. Mais on peut aussi prendre l'ouvrage comme un point de départ d'une vulgate durable? Il en serait ainsi d'une série de lieux communs destinés à une longue existence dans l'historiographie contre-révolutionnaire, avec des aspects quasi-misogynes comme la légende du déguisement des hommes pour mener les femmes à Versailles pendant les journées d'octobre 1789 (p. 406). Les notes, établies avec l'aide de Marcel Dorigny, signalent en tout cas une partie des sources documentaires françaises qu'a exploitées Mary Wollstonecraft pour ce travail : Mirabeau d'abord, au travers du Journal des États généraux, des Lettres à ses commettants et du Journal de Provence, et à un bien moindre titre Rabaut Saint-Étienne, avec le Précis de l'histoire de la Révolution française. D'autres sources identifiées en notes auraient peut-être pu plus judicieusement être citées directement, plutôt qu'au travers de renvois aux Archives parlementaires, trop postérieures: il est vrai que, souvent, cette collection ne mentionne pas l'origine des documents qu'elle reproduit !

7 Le volume éditorial choisi limitait certainement les possibilités et il faut regretter que, chez la grande épistolière qu'a été Wollstonecraft (cf. les douloureuses Letters to Imlay), le choix des deux lettres retenues pour traduction ne soit convaincant ni par les dates (au tout début d'un séjour français qui dure jusqu'en 1795), ni par le contenu: des lettres postérieures auraient introduit d'autres nuances, quitte à ne pas s'inscrire tout à fait dans le schéma confortable de l'attirance pour la Révolution suivie du désamour, quitte à marquer la violence des contradictions qui entourent le retour d'une Mary Wollstonecraft dans une Angleterre en proie, elle aussi, à la guerre totale...

8 C'est de toute manière une heureuse nouvelle que la mise à disposition de ces traductions, jusque-là introuvables et pour cause, équipées de surcroît de l'appareil de notes nécessaire à leur compréhension : plus de deux siècles après leur édition anglaise, La Défense des droits des hommes, comme la Vision historique... sont désormais disponibles pour le public francophone. Marie-Odile Bernez et les Éditions du CTHS peuvent à juste titre en être remerciées! 